\title{
Background firing rate affects the signal transfer of behavior locked input patterns from Purkinje cells to the cerebellar nuclei
}

\author{
Selva K Maran ${ }^{*}$, Ying $\mathrm{CaO}^{2}$, Detlef Heck², Dieter Jaeger ${ }^{1}$ \\ From Twenty First Annual Computational Neuroscience Meeting: CNS*2012 \\ Decatur, GA, USA. 21-26 July 2012
}

Multielectrode recordings from awake behaving mice revealed rhythmic modulation both in Purkinje cell (PC) simple spike (SS) activity and the cerebellar nuclei $(\mathrm{CN})$ neuron activity that is phase locked to the breathing rhythm. In the present work we were interested in studying how the different levels of background SS activity may affect the transfer of rhythmic SS modulation from $\mathrm{PCs}$ to the $\mathrm{CN}$ using a multicompartmental $\mathrm{CN}$ neuron model.

We created a population of fifty artificial gamma distributed PC spike trains and gave them to the $\mathrm{CN}$ neuron model as inputs with $5 \mathrm{nS}$ conductance strength [1]. The mean firing rate for a given input was based on the rate histogram distribution constructed from our experimental $\mathrm{PC}$ recordings in awake mice, and ranged from 28 to $170 \mathrm{~Hz}$. An identical slow fluctuation in the background firing rate for all 50 inputs was used, reflecting a high correlation of rates observed in vivo as quantified using a Bayesian rate estimation method [2]. The breathing associated rhythmic modulation estimated from a peri-event time histogram of a PC recording was normalized to a \% change from mean rate and convolved with baseline firing rate at the timing of recorded breaths.

The synaptic strength of the mossy fiber excitatory inputs was tuned so that the model output gave the best match to both the statistical properties and behavior related modulation of the experimental $\mathrm{CN}$ recordings. This match turned out to be excellent, as the mean ISI (recording 29.47, model 29.49), CV (1.072 vs. 0.926), and CV2 (0.74 vs. 0.75$)$ were near identical. The mean breathing related rhythmic modulation in the $\mathrm{CN}$ simulation turned out to be higher (60\%) than in the applied PC

\footnotetext{
* Correspondence: sseland@emory.edu

'Department of Biology, Emory University, Atlanta, Georgia, 30322, USA

Full list of author information is available at the end of the article
}

input trains (12\%). We then separated the breathing modulations obtained in the model output based on whether they occurred at low or high background firing rate. We observed a decrease in modulation depth from $70 \%$ to $30 \%$ when the baseline firing rate was high in the $\mathrm{CN}$. Similar results were observed in experimental recordings (a decrease from 60\% to 30\%) which also correlated with an decrease in PC firing rate and a decrease in rhythmicity of breathing during such episodes. To probe the cause of the inverse relationship between $\mathrm{CN}$ background rate and breathing modulation depth we used a PC input consisting of a $100 \mathrm{~s}$ ramp increase in rate with a fixed breathing modulation depth. This simulation revealed a linear inverse firing rate transformation between $\mathrm{PC}$ and $\mathrm{CN}$ rates, which also explains the dependence of breathing modulation on background rate. Essentially, since at high rates the absolute breathing related $\mathrm{PC}$ rate modulation is higher, this gets translated to greater relative rate modulation of $\mathrm{CN}$ neurons at their resulting low mean firing rate. Based on our findings we conclude that the background firing rate of PCs strongly affects the behavioral modulation of the output from the CN. This effect may be important in the cerebellar control or coordination of rhythmic motor behaviors such as breathing, licking, swallowing, and whisking.

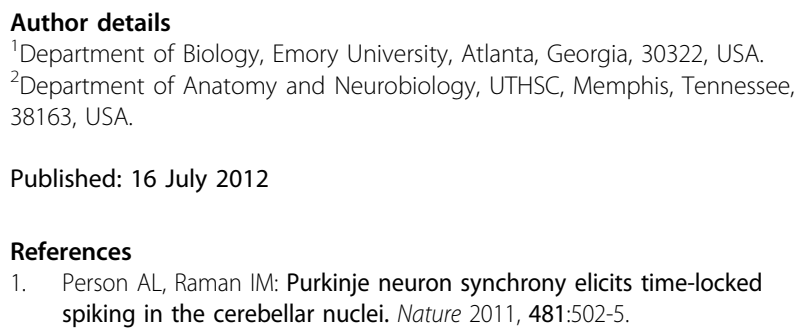

1. Person AL, Raman IM: Purkinje neuron synchrony elicits time-locked spiking in the cerebellar nuclei. Nature 2011, 481:502-5. 
2. Shimokawa $\mathrm{T}$, Shinomoto S: Estimating instantaneous irregularity of neuronal firing. Neural Comput 2009, 21:1931-1951.

doi:10.1186/1471-2202-13-S1-P112

Cite this article as: Maran et al: Background firing rate affects the signal transfer of behavior locked input patterns from Purkinje cells to the cerebellar nuclei. BMC Neuroscience 2012 13(Suppl 1):P112.

Submit your next manuscript to BioMed Central and take full advantage of:

- Convenient online submission

- Thorough peer review

- No space constraints or color figure charges

- Immediate publication on acceptance

- Inclusion in PubMed, CAS, Scopus and Google Scholar

- Research which is freely available for redistribution

Submit your manuscript at www.biomedcentral.com/submit

() BioMed Central 